\title{
Response to Janecka et al. 2017
}

\author{
H. Senn ${ }^{1} \cdot$ G. Murray-Dickson ${ }^{1}$ - A. C. Kitchener ${ }^{2} \cdot$ P. Riordan ${ }^{3}$ - D. Mallon ${ }^{4}$
}

Received: 7 July 2017 / Revised: 3 October 2017 / Accepted: 4 October 2017 / Published online: 11 December 2017

(c) The Genetics Society 2018

RE: Response to range-wide snow leopard phylogeography supports three subspecies

In response to Janecka et al. (2017), we welcome this much-needed study on the phylogeography of the snow leopard. Gathering and producing a data set of this size and quality on such an elusive species has clearly taken a longterm and large-scale collaborative international effort which should not, in any sense, be underestimated. The genetic data will undoubtedly benefit both scientific understanding and inform future conservation management of the species. It is, however, unfortunate and unnecessary to conclude, based on this data set, that the snow leopard comprises three separate subspecies. We feel this conclusion the overinterpretats an otherwise solid molecular data set and that this move goes against a more general feeling in conservation genetics, that it is advisable to avoid the use of the ill-defined, and problematic "subspecies" label (Table 1) and to move away from reliance on traditional population genetic data alone to generate units of any kind below the species level. Instead, multiple lines of genetic and nongenetic evidence that have some basis in fitness should be preferred (Ryder 1986; Zink 2004; Frankham et al. 2011, 2012, 2017; Carstens et al. 2013; Heller et al. 2013; Zachos et al. 2013; Zachos 2015). We set out the basis for our opinion below and discuss this further.

H. Senn

hsenn@rzss.org.uk

1 RZSS WildGenes Laboratory, Royal Zoological Society of Scotland, 134 Corstorphine Road, Edinburgh, UK

2 Department of Natural Sciences, National Museums Scotland, Chambers Street, Edinburgh, UK

3 Marwell Wildlife, Winchester, UK

4 Division of Biology and Conservation Ecology, Manchester Metropolitan University, Manchester, UK

\section{Sampling}

It should be noted that the sampling (70 samples from 21 locations) provides a far from complete coverage of the estimated 1.6-3 million $\mathrm{km}^{2}$ range. Except for four Nepalese samples from the eastern border, there is no sampling from the rest of the Nepali Himalaya and the NW Indian Himalaya, between the western border of Nepal and the Karakorum mountain range. The proposed boundary between two of the putative subspecies reported by Janecka et al. (2017), coincides with this sampling gap, which is problematic for the interpretation of the data. Similarly, samples were only collected from the western Tien Shan range, with no samples from the mountain ranges to the west and south of the Dzungarian Basin, which has been highlighted as a region of importance for understanding population connectivity for snow leopard (Riordan et al. 2015). Janecka et al. (2017) also present this area as a boundary between putative subspecies, which we again think should be interpreted with a degree of caution based on the distribution of samples used. Given the difficulty of collecting samples in this region of the world we do not criticise the authors for these gaps, it should, however, be acknowledged that they may be contributing to the pattern of divergence shown since the authors are primarily relying on the evidence from genetic markers to make their claim, this is relevant, if potentially difficult to overcome.

\section{Lack of mtDNA diversity}

The almost complete absence of mtDNA diversity across the 70 samples at $96 \mathrm{bp}$ of Cytochrome b, $224 \mathrm{bp}$ of hypervariable region II and 323-bp of the central conserved region of d-loop (control region) is a striking finding. The authors cite various possible reasons to explain this, such as insufficient sequencing of the mitogenome, the selection pressure of hypoxia, adaptive introgression following hybridisation with the African lion Panthera leo lineage ( $\mathrm{Li}$ et al. 2016) or a population bottleneck. One viewpoint 


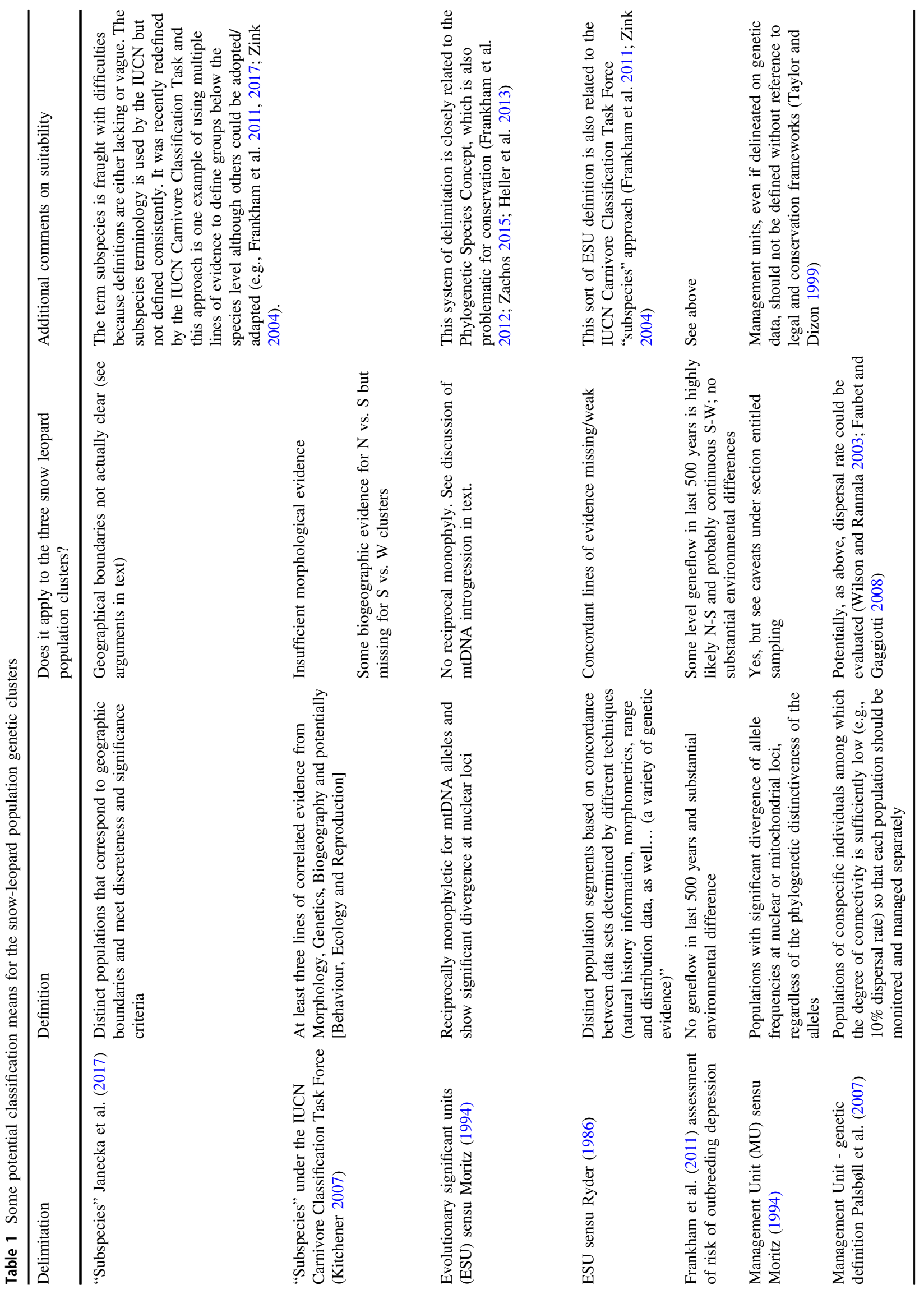


might be, that far from showing discordance, the mtDNA data instead simply corroborates a picture of relatively low genetic diversity in snow leopards (mean number of alleles per locus $=5.8$ ) following an expansion from an estimated 8000 -year-old bottleneck (estimated range $=4574$ to 11,893 ya). Divergence at mtDNA is one of the only reasonably universally comparable benchmarks available to the delimitation of mammalian taxa (Bradley and Baker 2001). While there are clearly alternative explanations than can be offered, and monophyly at mtDNA should not be a sufficient criterion for delimitation of taxa (Moritz 1994), evidence from mtDNA should still, in general, be given consideration alongside other lines of evidence. Critically, in this case, the differentiation at nuclear markers, which is essentially rather hard to benchmark, is not corroborated by other lines of non-genetic evidence (see below), which might allow us to more easily disregard the mtDNA findings. While we agree that various explanations of the mtDNA evidence are possible, we feel again, that relying on microsatellite data alone is not appropriate.

\section{Genetic structure within the microsatellite data}

A variety of well-established population genetic methods recover concordant patterns of hierarchical genetic population structure, which could reasonably be read as providing evidence of division into 2, 3 or 6 population clusters. There is evidence of admixture between the clusters (Janecka et al., Fig. 2d). We would interpret this picture as showing population-level differentiation, that in the absence of other corroborating lines of evidence should not be elevated above this status. We would, of course (considering the issues with sampling gaps discussed above), encourage full consideration of these data in the continuing management and the potential future designation of Management Units for snow leopards. Management Units should, however, always also take into consideration the practicalities of implementation (i.e., legal and conservation frameworks) (Taylor and Dizon 1999; McCarthy and Mallon 2016) and potentially other lines of evidence (Table 1).

\section{Taxonomy}

There is considerable disagreement about whether subspecies are a valid or useful taxonomic division at all, not least since there is no clear consensus on definition (see for example a recent discussion on grey wolf Canis lupus subspecies in this journal; Cronin et al. 2015 and review by Haig et al. 2006). However, Janecka et al. (2017) do not, in our opinion, meet their own criteria: "Subspecies are generally considered distinct populations that correspond to geographic boundaries and meet discreteness and significance criteria". Here, we see limited evidence of clear geographical boundaries between putative subspecies and no additional corroborating lines of evidence are available (e.g., there only very limited suggestions of phenotypic difference between Northern and Southern clusters; Kitchener et al. 2017 and no marked environmental difference; Frankham el al. 2011). The Gobi Desert in China and Mongolia is interspersed with many rocky mountains, all of which are occupied by snow leopards. They are known to disperse between these habitat patches (e.g., Wang and Schaller 1996; Snow Leopard Network 2014) and so the Gobi does not in fact present a clear 'barrier effect'. The absence of a major landscape feature correlating with the putative $P$. u. uncia and $P$. u.'uncioides' boundary is especially marked. The authors state that the Transhimalaya are near-continuous and propose no specific barrier, except for the somewhat imprecise suggestion of major rivers. However, the upper reaches freeze during winter, facilitating dispersal and the notional barrier would apply only to a small part of this putative boundary, since farther north, the Qinghai-Tibetan Plateau is an open landscape interspersed with mountains. Furthermore, Janecka et al. (2017) suggest that the western cluster includes the Pamirs, which lie at the junction of several major ranges (Tien Shan, Pamir-Alai, Hindu Kush, Kun Lun) forming the so-called 'Pamir Knot', long been considered a major biogeographical link-the very opposite of a barrier. The approximate boundary of the proposed subspecies shown on the map (Fig. S6) appears to cut arbitrarily across the western part of the Qinghai-Tibet Plateau, and continues equally arbitrarily across the western Himalaya, coinciding with the political border of Nepal.

It also seems unclear that the clusters would meet the criteria of evolutionary significant units (ESU) or the criteria of other proposed means of classification below the species level (Table 1). The debate over the utility of subspecies and related concepts is unlikely to be resolved any time soon. However, in general there is caution within the conservation community against the use of single lines of molecular genetic evidence to justify splitting previously accepted taxonomic arrangements, since this rarely serves a conservation purpose for the species in question (Frankham et al. 2012; Carstens et al. 2013; Zachos et al. 2013). In a recent review of the taxonomy of the Felidae, Kitchener et al. (2017) have reduced the number of recognised subspecies from 208 listed by Wozencraft (2005) to 77, owing to the lack of combined molecular, morphological and biogeographical evidence in support of most previously recognised subspecies.

\section{Nomenclature}

Finally, we must also note that the proposed nomenclature for the three posited subspecies is incorrect. The name irbis 
(Ehrenberg 1830) was suggested as a replacement for uncia and is a junior synonym of $P$. uncia (Schreber 1775) because Pocock (1930) fixed the type locality of uncia as the Altai Mountains. Horsfield (1855) did not designate a type specimen for Felis uncioides from Nepal and hence this is a nomen nudum. The next available name is schneideri (Zukowsky 1950) for populations from the Himalayas, so the western population as defined by Janecka et al. (2017) would require a new subspecies name. However, we believe that there is insufficient evidence to warrant this taxonomic revision and, until other evidence becomes available, we would suggest Panthera uncia continues to be regarded as a monotypic species.

In closing, we would encourage authors claiming new taxonomic designations, that they not only outline the species/subspecies definition(s) that they make their claims under, but also explore their justifications for choosing them, and test them against multiple definitions. There are many other studies whose conclusions might also be clarified for the conservation community by using this approach (e.g., Koepfli et al. 2015; Fennessy et al. 2016). This information will facilitate the interpretation of the study in question by conservation managers. IUCN specialist groups can help this process by generating and applying appropriate and consistent guidelines on the appropriate taxonomic criteria for conservation purposes (e.g., IUCN/SSC ASG 2017; Kitchener et al. 2017), these are currently much needed.

\section{Compliance with ethical standards}

Conflict of interest The authors declare that they have no conflict of interest.

\section{References}

Antunes A, Pontius J, Ramos MJ, O’Brien SJ, Johnson WE (2007) Mitochondrial introgressions into the nuclear genome of the domestic cat. J Hered 98:414-420

Bradley RD, Baker RJ (2001) A test of the genetic species concept: cytochrome- b sequences and mammals. J Mammal 82:960-973

Bylemans J, Maes GE, Diopere E, Cariani A, Senn H, Taylor MI, Helyar S et al. (2016) Evaluating genetic traceability methods for captive-bred marine fish and their applications in fisheries management and wildlife forensics. Aquac Environ Interact 8:131-145

Carstens BC, Pelletier TA, Reid NM, Salter JD (2013) How to fail at species delimitation. Mol Ecol 22:4369-4383

Cronin MA, Cánovas A, Bannasch DL, Oberbauer AM, Medrano JF (2015) Wolf subspecies: reply to Weckworth et al. and Fredrickson et al. J Hered 106:417-419

Ehrenberg CG (1830) Observations et données nouvelles sur le tigre $\mathrm{du}$ nord et la panthère du nord, recueillies dans le voyage de Siberie fait par M. A. de Humboldt, en l'année 1829. Annales des Sciences Naturelles 21:387-412
Faubet P, Gaggiotti OE (2008) A new Bayesian method to identify the environmental factors that influence recent migration. Genetics 178:1491-1504

Fennessy J, Bidon T, Reuss F, Kumar V, Elkan P, Nilsson MA, Vamberger M, Fritz U, Janke A (2016) Multi-locus analyses reveal four giraffe species instead of one. Curr Biol 26:2543-2549

Frankham R, Ballou JD, Eldridge M, Fenster CF (2011) Predicting the probability of outbreeding depression. Conserv Biol 25:465-475

Frankham R, Ballou JD, Dudash MR, Eldridge MDB, Fenster CB, Lacy RC, Mendelson III JR, Porton IJ, Ralls K, Ryder OA (2012) Implications of different species concepts for conserving biodiversity. Biol Conserv 153:25-31

Frankham R, Ballou JD, Ralls K, Eldridge M, Dudash MR, Fenster CB, Lacy RC, Sunnucks P (2017) Genetic management of fragmented animal and plant populations. Oxford, UK: Oxford University Press

Funk WC, Mckay JK, Hohenlohe PA, Allendorf FA (2012) Harnessing genomics for delineating conservation units. Trend Ecol Evol 27:489-496

Haig SM, Beever EA, Chamber SM, Draheim HM, Dugger BD (2006) Taxonomic considerations in listing subspecies under the U.S. Endangered Species Act. Conserv Biol 20:1584-1594

Heller R et al. (2013) Are there really twice as many bovid species as we thought? Syst Biol 62(3):490-493. https://doi.org/10.1093/ sysbio/syt004

Horsfield T (1855) Brief notices of several new or little-known species of Mammalia, lately discovered and collected in Nepal, by Brian Houghton Hodgson. Ann Mag Nat Hist (2nd series) 16:101-114

IUCN/SSC ASG 2017. Taxonomy Policy. Version 2.0. IUCN/SSC Antelope Specialist Group. Available from: https://www.iucn. org/ssc-groups/mammals/antelope-specialist-group

Janecka et al. (2017) Range-wide snow leopard phylogeography supports three subspecies. J Hered; https://doi.org/10.1093/ jhered/esx044

Kitchener AC, Breitenmoser-Wursten Ch, Eizirik E, Gentry A, Werdelin L, Wilting A, Yamaguchi N, Abramov AV, Christiansen P, Driscoll C, Duckworth JW, Johnson W, Luo S-J, Meijaard E, O’Donoghue P, Sanderson J, Seymour K, Bruford M, Groves C, Hoffmann M, Nowell K, Timmons Z, Tobe S (2017) A revised taxonomy of the Felidae. The final report of the cat classification task force of the IUCN/SSC Cat Specialist Group. Cat News Special Issue 11:1-80

Koepfli K-P et al. (2015) Genome-wide evidence reveals that African and Eurasian Golden Jackals are distinct species. Curr Biol 16:2158-2165. https://doi.org/10.1016/j.cub.2015.06.060

Li G. et al. (2016) 'Phylogenomic evidence for ancient hybridization in the genomes of living cats (Felidae)' 26(1):1-11. https://doi. org/10.1101/gr.186668.114

McCarthy T, Mallon D (2016) Snow leopards. Academic Press, New York, NY

Moritz C (1994) Defining "Evolutionarily Significant Units" for conservation. Trend Ecol Evol 9:373-375

Palsbøll PJ, Bérubé M, Allendorf FW (2007) Identification of management units using population genetic data. Trend Ecol Evol 22:11-16

Pocock RI (1930) The panthers and ounces of Asia. Part II. J Bombay Nat Hist Soc 34:307-336

Riordan P, Cushman S, Mallon D, Shi K, Hughes J (2015) Predicting global population connectivity and targeting conservation action for snow leopard across its range. Ecography 38:1-8

Ryder OA (1986) Species conservation and systematics: the dilemma of subspecies. Trend Ecol Evol 1:9-10

Schreber JCD (1775) Die Säugethiere in Abbildungen nach der Natur mit Beschreibungen. Vol.2 (14) Wolfgang Walther, Erlangen. 
Snow Leopard Network (2014). Snow leopard survival strategy. Version2014.1. Snow LeopardNetwork, www.snowleopardnetw ork.org.

Taylor B, Dizon A (1999) First policy then science: why a management unit based solely on genetic criteria cannot work. Mol Ecol 8:S11-S16

Toews DP, Brelsford A (2012) The biogeography of mitochondrial and nuclear discordance in animals. Mol Ecol 21:3907-3930. https://doi.org/10.1111/j.1365-294X.2012.05664.X

Wang XM, Schaller GB (1996) Status of large mammals in in western Inner Mongolia, China. J East China Norm Univ Nat Sci 12:93-104

Wilson GA, Rannala B (2003) Bayesian inference of recent migration rates using multilocus genotypes. Genetics 163:1177-1191

Wozencraft WC (2005) Order Carnivora. In: Wilson DE, Reeder DM (eds.) Mammal species of the world. A taxonomic and geographic reference, 3rd edn. Johns Hopkins University Press, Baltimore, USA, p 532-628

Zachos FE, Apollonio M, Bärmann EV, Festa-Bianchet M, Göhlich U et al. (2013) Species inflation and taxonomic artefacts-A critical comment on recent trends in mammalian classification. Mamm Biol - Zeitschrift für Säugetierkunde. 78(1):1-6. https://doi.org/ 10.1016/j.mambio.2012.07.083

Zachos FE (2015) Taxonomic inflation, the Phylogenetic Species Concept and lineages in the Tree of Life - a cautionary comment on species splitting. J Zool Syst Evol Res 53(2):180-184. https:// doi.org/10.1111/jzs. 12088

Zink RM (2004) The role of subspecies. Proc R Soc London 271:561-564

Zukowsky L (1950) Grossäuger, die Hagenbeck entdeckte. Der Zoologische Garten (Neue Folge) 17:211-221 